\title{
Inscribing Trans and Intersex People in the Dominant Binary Categories of Gender
}

\author{
Corinne Fortier \\ French National Center of Scientific Research (CNRS) \\ Social Anthropology Lab (CNRS-EHESS-Collège de France, Paris)
}

\section{Bi-gendered or Third-gendered Body}

$\mathrm{T}$ he predicament of trans and intersex people raises the question of the domination of social values inherent in gender binaries. The belief in a fixed gender identity is pervasive among most psychiatrists, medical doctors, judges, and psychologists.

John Hopkins paediatric endocrinologist John Money was the first one to conceptualize the notion of genderin the 1950s in relation to intersex children (Money \& Ehrhardt, 1975), and psychiatrists, psychologists and medical doctors in Western countries have built on his ideas in the following decades. Robert Stoller's distinction between sex and gender (1968) was especially groundbreaking, because it allowed one to understand and describe the lived experience of trans and intersex individuals (1975).

In the field of anthropology, it is undoubtedly American anthropologist Margaret Mead who emerges as a precursor in examining sex and gender in non-Western societies in the 1940s. The cultural construction of sex and gender was then taken up in the 1970s and 1980s by other anthropologists (Ortner 1974, 1981; Ortner \& Whitehead, 1981). In the 1990s, American philosopher Judith Butler has demonstrated that gender is not natural but rather the result of a compounding of acts, very much like rituals, which are performatively repeated collectively so as to maintain a binary gender model. The awareness of one's gender identity is reached not only through performative acts but also through infralinguistic codes of a visual order (the colors pink or blue of clothes for example). The making of gender is mediated through the real body via the criss-crossing of discursive and visual representations inherited from family, religion, the educational system, the media, medicine, legislation and, less evidently, language, the arts, literature, and cinema (De Lauretis, 1987).

All societies know the binary classification of gender which consists in classifying the individuals as man or woman, with the exception of certain societies which recognize the existence of a third gender. The American anthropologist Gilbert Herdt (1994) introduced the term of third sex or third gender in the 1990s, and in France and in Quebec, anthropologist Saladin d'Anglure $(1992,1998,2005)$ applied third sex expression to Inuit society. Various local names are given to these individuals : it may be the term Two-Spirit for Amerindian, hijra in India, fa 'afafine in Polynesia, lady boy in Thailand, transvestite in Brazil, gordiguen which means "man-woman" in Mauritania (Fortier, 2005), femminielli which means "effeminate" in Naples in South Italia (Fortier, 2013). 
An individual gender identity cannot be subsumed to sexual anatomy such as the penis, sperm (Fortier, 2005), body hair for a man (Fortier, 2010), the uterus, vagina, oocyte, menstruation, breasts for a woman. These attributes, however, concur to shape the imagined identity and are thus often incorporated by trans individuals seeking to masculinize or feminize themselves within the confines of medical technology either, for $\mathrm{FtMs}^{1}$, through male hormone treatment, mastectomy, phalloplasty or, for MtFs, hair removal, wigs, hair implant, hormonal treatment, mammary prosthetics, Adam's apple surgery (chondroplasty) and facial surgery.

Among intersex boys, the presence of a penis contributes to the feeling of being male without it being a sine qua non condition. Likewise, the absence of a vagina does not prevent intersex girls from feeling womanly (Stoller, 1968). Moreover, anatomical characteristics vary considerable across the population (consider for example female body hair or male breasts). Whilst sexual anatomy is often thought to be unambiguous and immutable, it is in actuality extremely relative and cannot therefore be considered as absolute criteria to assess the gender of an individual, whether trans or not. Actual bodies, even those whose sex is not questioned from a medical point of view, never fulfil the ideal gender norms. Thus, to demand unambiguity and irreversibility of sexual appearance from trans- and inter- persons reveals itself as an ideological effort.

\section{One Sex Reassignment Surgery}

My anthropological researches with trans people, taught me that it is in vain to want to distinguish clearly between the categories of transvestites, transgenders and transsexuals, as far as these categories are porous. All these people share a fundamental common denominator, which is the one of the transidentity; that they live socially in a gender identity which does not correspond to their sex at birth.

Research with French trans individuals has shown that anatomical sex is not a major factor in the shaping of trans identity despite what the very term transsexual may suggest. Except for certain trans MtF who hate their penis (people who can even have practised selfmutilation, and to whom the operation of sex represents a revival), numerous trans people do not experience the need to change anatomical sex, they rather want to change physical appearance and socio-legal status. What matters for them is to be recognized socially and legally according to the gender identity which they consider as theirs.

Conseqently, many trans people fundamentally need a social and legal recognition which does not pass inevitably by a sexual operation. This one is usually named by the doctor's sex reassignment surgery. Still, terms like sexual reassignment, surgical reconstruction or, more seldom, sexual reattribution are all expressions that emphasize the fact that trans individuals are reconstructed and reassigned a sexed body in which they ought to have been born, according to a dualist division of mind and body. This dualism is very much shared by both doctors and patients (Fortier, 2014).

As far as the obtaining of the modification of the legal sex for a trans in France today is officially constituted through one's surgery, many trans have an operation with the ultimate purpose of obtaining the legal recognition of their gender identity. If, for some, the operation

${ }^{1}$ A trans MtF means "Male to Female", and a trans FtM, a "Female to Male". 
represents a revival, for others it is similar to a mutilation which they silently have to agree to in order to obtain what they desire most. We measure there, the scale of the biopower (Foucault, 1976), which exercises the law on the individual bodies. The operation of sex is a matter of a personal choice appropriate to every individual, and it should not be established as the key giving access to the change of legal sex. As recommended in March 2007 by the "Principles on the application of international human rights law in relation to sexual orientation and gender identity", named "Yogyakarta principles": "No one shall be forced to undergo medical procedures, including sex reassignment surgery, sterilisation or hormonal therapy, as a requirement for legal recognition of their gender identity"2.

Regarding trans people, women may have a male genital organ, or conversely a man may have a female genital organ. This last possibility, to be a man while having feminine genital organ, is increasingly recognized by French judges, but only for technical reasons. Phalloplasty surgery is not efficient enough to give to trans FtM an erectile penis, which would sign their masculinity. As a consequence, the change of their legal sex can be given to people who kept their vagina. Because the possibility of becoming a man without phalloplasty is authorized from medical and juridical point of view, the possibility that becoming a woman without "castration" should also be symmetrically accepted.

But this argument is never moved forward by French judges, who still prefer to base their decisions on visible proof, when the medical techniques allow it, and as the operation of vaginoplasty is considered as more easily accomplished and ordinary than the inverse operation, the judges still mainly justify the change of legal sex for a trans $\mathrm{MtF}$ on this operation.

The women were often reduced to their reproductive function. So, many societies have difficulty in considering that a trans FtM can keep its womb and its ovaries. Nevertheless, the recent case of Thomas Beatie in the United States, shows that it is possible to be a man, and besides being the husband of his wife and father of his children also keep and even use the "feminine" reproductive functions as well as the ovaries of his body. Thomas Beatie carried and gave birth to three children between 2008 and 2010, thanks to a sperm donation and thanks to a temporary stop to testosterone. Thomas Beatie used his own uterine function instead of his wife, who had practiced hysterectomy.

We know the deep reactions provoked by this new situation in the media, because Thomas Beatie had just given reality to the figure of "the pregnant man", which was previously left in the limbo of the imagination, even if it was deeply present in popular representations, tales, and myths. One newspaper article stated: "When daddy is also the mommy", which shows the difficult dissociation between the parental function, and becoming a father by having used biological reproductive functions traditionally characterizing motherhood. In the case of Thomas Beatie, the uterine function of reproduction can be disconnected from the gender identity, even if this function remains gendered; Thomas Beatie terms his own reproductive fonction as having become a surrogate mother.

\footnotetext{
${ }^{2}$ http://data.unaids.org/Pub/manual/2007/070517_yogyakarta_principles_en.pdf

3 "When daddy is also the mommy", Ellen Goodman, The Boston Globe, July, 11, 2008, http://www.boston.com/bostonglobe/editorial_opinion/oped/articles/2008/07/11/when_daddy_is_also_the_mommy/
} 


\section{Illusory Quest for One Definite Gender}

To French transsexuals, physical castration is usually preceded by chemical castration in the form of devirilizing hormones. The drug Androcure for example neutralizes the production of testosterones before the trans $\mathrm{MtF}$, who wishes to feminize her appearance, is prescribed feminizing hormones. The same applies to trans FtMs, who first have to undergo a mastectomy followed by a hysterectomy before considering a phalloplasty. The individual is required by the medical establishment to discard forever her social feminity, that is, the breasts and uterus, before such an individual is allowed to acquire the emblematic insignia of masculinity, that is, the penis. The very term of phalloplasty, which relates to the phallus as a symbol rather than the penis as an organ, reveals the over-determined association of that sex organ to virility.

This is because individuals must first be deprived of their original anatomical characteristics before acquiring those of their new gender identity, whereby what is physically removed from the individual is that which was supposedly inherent in the opposite sex, before such an individual develops the gender that is his or her own.

Similarly, in France, as in many other countries, medical doctors, when faced with sexual ambiguities, are prone to intervene in order to correct the "unfinished" sexual development by giving the child a definite sexual phenotype, usually feminine. They assume that genital surgery and endocrine therapy in early infancy ensure an unambiguous rearing as boy or girl and thereby a "normal" and healthy psychosexual development resulting in a stable and definite masculine or feminine gender identity.

Each person who experiences doubts about gender identity and feelings of intersexuality, or who experiences what Judith Butler called gender trouble (1990), cannot remain bigendered, but inevitably has to be monogendered.

The lurking fear of indeterminacy haunts both medical doctors and judges who seek to caution hormonal therapy or sex reassignment surgery in order to entrench in the flesh the putative unambiguity and irreversibility of "sex". An important premise is the juridical requirement of the irreversibility of sex reassignment surgery that stands as a supplement for the idea of sex being a natural fact (Fortier, 2012). Upon closer scrutiny, it turns out that the irreversibility of "sex" is a fiction. First, hormonal therapy, even though it is qualified as definitive is not irreversible since it is a life-long treatment and primary characteristics at birth resurface as soon as individuals stop the treatment.

A case in point is, again, the American FtM Thomas Beatie who, as a result of stopping the intake of testosterone, rediscovered his ovarian function and was able to bear a child. The same applies to mammary prosthetics: it is conceivable that a MtF with mammary prosthetics would wish to one day remove them, just as an FtM having undergone a mastectomy could later contemplate putting in mammary prosthetics. In other words, the sex change operation is not as absolute as one would imagine.

Mastectomies, as well as the removal of testicles, ovaries or the uterus are irreversible with regards to biological functionality (especially biological reproduction), but with the contemporary proliferation of reproduction technologies even here irreversibility becomes a relative term. Laser depilation is truly irreversible since hair does not grow back. But this is interpreted as an aesthetic criterion and not a medical one. 
However, the borders between what is medical and what is cosmetic are innately porous and imbued with relativism. For instance, some men take in oestrogen in order to have a smoother skin for cosmetic rather than medical reasons. Or some individuals may be on testosterone for the sake of experimenting and not to "become a man", as Beatriz Preciado did (2008). Similarly, one can quibble over the therapeutic and therefore not strictly cosmetic dimension of facial surgery, just as the cosmetic and the therapeutic cannot be easily separated in sex surgery.

\section{Intersex and Trans activism}

Western societies have problems conceptualizing the very notion of indeterminacy or fluidity in gender identity (Fortier, 2012). Individuals refusing to be catalogued under a definite gender can arouse a "queer" feeling of strangeness among others. All the recent legal evolutions in this domain, especially in Australia, in Europe, in South America, or in the Indian subcontinent are due to the collective mobilizations of queer, trans and intersexual people, fighting to question the domination of gender bipolarization.

Intersex individuals have, since the beginning of the 1990s in Europe protested against the medical model of early genitoplastic corrections. They criticized the medical establishment and their own parents for interfering with their bodily integrity and their genitalia while depriving them of their choice of gender identity. After more than fifteen years of activism in Germany, the national German Ethical Council stipulated in 2012 that the surgical manipulation of children's indefinite genital organs constitutes a violation of the right to bodily integrity. The Council thus advocated the right to an open future. Other countries are busy modifying their laws and medical practices related to intersex individuals; this is the case in Switzerland in 2013, and in the United States and Canada since the 1990s. In France, the Associations for Intersex Individuals have been asking for medical and social practices to be changed but no change has so far been implemented.

The most progressive law on gender identity does not come from a European country, but from a Latin American one, Argentina. Anyone in Argentina, just by manifesting his or her will through an affidavit, may request in the Civil Registry the change of gender and name in his or her identity card and birth certificate. Unlike what happens in other countries, he or she will not need the intervention of any judge, or a medical diagnosis, or witnesses, or have to wait a certain period before being granted the change of documentation. The "gender identity law", drafted in December 2011, states that: "In no case will it be needed to prove that a surgical procedure for total or partial genital reassignment, hormonal therapies or any other psychological or medical treatment has taken place". The Argentine law marks a real break with the medical and psychiatric approach of transidentity as transsexuality.

But still, in Argentina, as in many countries, each person has to conform psychologically, physically, socially, and legally to this bicategorization, without any other choice. Could the category of third gender or trans become a legal category ? This right for the " $\mathrm{T}$ " for trans was acquired by the hijra - a group, which remains widely stigmatized - , in the Indian State of Tamil Nadu since 2008, in Pakistan since 2010, and in Nepal in 2011. Could this legal category of " $\mathrm{T}$ " for trans be possible not only in the societies where the third gender is socially already recognized but also in some Western societies where the existence of a third gender remains socially problematic? 
In 2011, Australia has added the category "X" for "indefinite sex" besides the categories of man or woman on passports for intersex or trans individuals. The right for the indecision of its gender identity differs from the recognition of a third gender identity, namely trans. MayWelby was the first person in New South Wales, at the age of 48, to be recognized officially as having a "sex non-specified"

May-Welby, who was born a boy, underwent MtF hormono-surgical treatment in 1989, when she was 23 years old. She then took the name Norrie May-Welby. But "she" stopped the hormonal treatment after her sex shift. Later, "her" new woman identity no longer suited her. May-Welby explained: “Those concepts, man or woman, just don't fit me, they are not my actual reality, and, if applied to me, they are fiction... I've never felt completely male or female, except for a brief period in early transition, when I first identified as a transsexual because I thought there were only two gender options and male was wrong and female felt better. Apart from those few brief years where I shared the delusions of transsexual medicine, in which so many doctors are convinced everyone has a core identity either male or female, I have always been androgynous" ". May-Welby is now referred to as "zie" (rather than she/he) and "hir" (rather than her/him). "Zie" suppressed the feminine part of "hir" name Norrie, and took the new name of May-Welby, and militates now for the right not to be assigned a gender category. As May-Welby explained: "There seemed no sense in having such a changeable and transient quality as gender nailed down as a permanent mark on identity documents"

In 2010 the Australian Registry of Births, Deaths and Marriages rescinded its promise to supply May-Welby with a registered detailed certificate that had a "not specified" identification in the sex category. May-Welby had originally received the certificate, but then received a formal letter of cancellation. In response, May-Welby filed a complaint with the Australian Human Rights Commission. May-Welby is a member of the association Sex and Gender Education (SAGE), which is a group that supports and campaigns for the recognition of gender diversity. With the full support of SAGE, May-Welby's fight succeeded, and the Australian government announced in September 2011 that the new passports would contain henceforth three categories of sex: M, F and X. But the benefit of this mention is still subordinate to a medical attestation.

Today, another person is currently fighting for a similar type of legal recognition in England. Born biologically as a girl, Christie Elan-Cane grew up acutely aware that she was set apart from other children : "I felt I didn't belong anywhere. I identified not with being a boy but with differentness" "She" realised that, although "she" felt no desire to become a man, "she" had the desire for a change of identity. "She" found a psychiatrist, who put "her" on the male hormone testosterone, and arranged for a mastectomy. "He" felt liberated without breasts and "wearing clothes for the first time felt right".

\footnotetext{
${ }^{4}$ Courrier international, n 1102, du 15 au 21 décembre 2011, "Il ou elle - Enquête sur l'émergence des transgenres": 16.

5 “My journey to getting a 'sex not specified' legal document", The Scavenger, feb $04^{\text {th }} 2010$, http://www.thescavenger.net/glbsgdq/my-journey-to-getting-a-sex-not-specified-document-86598-207.html

${ }^{6}$ ibid.

7 “I'm just a sweet transgenderist", The Independent, 03 february 2014 (http://www.independent.co.uk/life-style/imjust-a-sweet-transg.)
} 
"He" thought "he" had found his identity. But finally: "I realised that I wasn't male or female, but that I could be androgynous. I stopped trying to dress as a man, wearing male clothes, and changed my name to Zoltar, a name which refers to an androgynous Japanese cartoon character". Zoltar refused to accept the title of Miss or Mr., and asserts: "Many English people see me as a product of everything they detest" ". Many British psychiatrists still regard the desire to live between genders with scepticism, like Dr Russell Reid, a psychiatrist who worked at the United States' first gender identity clinic, at Johns Hopkins University, Maryland, and now practises privately in London. He believes that "most androgynes suffer from a personality disorder or are rebelling against society" 9 .

If we admit the possible undecidability of gender identity, adding a category " $\mathrm{X}$ " for indefinite, or " $T$ " for trans, will not completely solve the problem, because the issue here is not the contents of the category strictly speaking, but indeed the existence of such a category. That is, to have to define oneself along these terms. This problem may be partially solved if the mention of sex did not appear any more in official civil documents. May-Welby in Australia, and other trans activists around the world struggle nowadays for this legal amendment. As May-Welby explained: "The concepts of man or woman don't fit me. The simplest solution is not to have any sex identification"10. This "simplest" solution, which challenges the gender structure of our societies, may be our future and our new values.

\section{Works Cited}

Butler, Judith. Gender Trouble. Feminism and the Subversion of Identity. New York: Routledge, 1990.

De Lauretis, Teresa. Technologies of Gender. Essays on Theory, Film and Fiction. Bloomington: Indiana University Press, 1987.

Fortier, Corinne. "Le don de sperme et le don d'ovocyte ou "trois font un". Sexualité, inceste et procréation". Patrice Bidou, Jacques Galinier et Bernard Juillerat, eds.

Anthropologie et psychanalyse : regards croisés. Paris, EHESS, 2005, 59-80.

----. "La barbe et la tresse. Marqueurs de la différence sexuée (société maure de Mauritanie)". Les Cahiers du Laboratoire d'Anthropologie Sociale 6 (2010): 94-104.

----. "I femminielli o la rivalità seduttrice: affetti, identità e sessualità a Napoli ed in Campania. Approccio antropologico, letterario e psicoanalitico". Eugenio Zito e Paolo Valerio, eds. Genere: femminielli. Esplorazioni antropologiche e psicologiche. Napoli: Libreria Dante \& Descartes, 2013, 186-212.

----. 'La question du 'transsexualisme' en France”. Les Cahiers de droit de la santé, 18 (2014) : 269-282.

\footnotetext{
${ }^{8}$ ibid.

${ }^{9}$ ibid.

10 "Briton is recognised as world's first officialy genderless person", The Telegraph, 15 Mar 2010 , http://www.telegraph.co.uk/news/newstopics/howaboutthat/7446850/Briton-is-recognised-as-worlds-first-officiallygenderless-person.html
} 
Fortier, Corinne et Laurence Brunet. "Changement d'état civil des personnes trans en France : du transsexualisme à la transidentité". Nicole Gallus et Alain-Charles Van Gysel, eds. Droit des familles, genre et sexualité. Limal: Anthemis, 2012, 63-113.

Foucault, Michel. Histoire de la sexualité. t. 1. La volonté de savoir. Paris: Gallimard (Tel), 1976.

Herdt, Gilbert. "Introduction: Third Sexes and Third Genders". Gilbert Herdt, ed. Third Sex, Third Gender: Beyond Sexual Dimorphism in Culture and History. New York: Zone Books, 1994, 11-20.

Mead, Margaret. Male and Female. A Study of Sexes in a Changing World. New York: William Morrow \& Company, 1949.

Money, John and Anke Ehrhardt. Man and woman, Boy and Girl: the Differentiation and Dimorphism of Gender Identity from Conception to Maturity. Baltimore: Johns Hopkins University Press, 1972.

Ortner, Sherry Beth. "Is Female to Male as Nature is to Culture?". Michelle Zimbalist Rosaldo and Louise Lamphere, eds. Women, Culture and Society. Stanford: Stanford University Press, 1974, 67-88.

----. "Gender and Sexuality in Hierarchical Societies: The Case of Polynesia and Some Comparative Implications". Sherry Beth Ortner and Harriet Whitehead, eds. Sexual Meanings: The Cultural Construction of Gender and Sexuality. Cambridge: Cambridge University Press, 1981, 359-409.

Ortner, Sherry Beth and Harriet Whitehead. "Introduction: Accounting for Sexual Meanings". Sherry Beth Ortner and Harriet Whitehead, eds. Sexual Meanings: The Cultural Construction of Gender and Sexuality. Cambridge: Cambridge University Press, 1981, 1-28.

Preciado, Beatriz. Testo Junkie. Sexe, drogue et biopolitique. Paris: Grasset, 2008.

Saladin d'Anglure, Bernard. "Le "troisième" sexe". La Recherche 245 (juil-aout 1992): 836844.

----. "Présentation et débats. Médiations chamaniques. Sexe et genre". Anthropologie et Sociétés 22 (2) (1998): 5-23.

----. " Un "troisième sexe" social chez les Inuit ("transsexualité, travestissement et chamanisme")". Françoise Héritier ed., Hommes, femmes, la construction de la différence. Paris: Le Pommier (Cité des sciences et de l'industrie), 2005, 114-124.

Stoller, Robert. Sex and Gender: the Development of Masculinity and Feminity. New York: Science House, 1968.

----. Sex and Gender: the Transsexual Experiment. London: Hogarth Press, 1975. 